\title{
ENTREVISTA COM A PROFESSORA AURORA F. BERNARDINI
}

Sobre Marina Tsvetáieva e sobre o livro Indicios Flutuantes, ganhador do Prêmio Jabuti-2007 na categoria de melhor livro de poesia.

Belkiss Rabello: Professora Aurora, a senhora dedica o livro "Indicios Flutuantes” à memória de Liuba Kusnetsova e em memória das "inesqueciveis tardes" que ambas passaram com Marina Tsvetáieva. Fale-nos um pouco sobre Liuba Kusnetsova e sobre essas tardes "em companhia" de Marina Tsuetáieva.

Aurora Bernardini: Liuba Kusnetsova era uma senhora que viera ao Brasil logo depois do fim da Segunda Guerra, convidada por um irmão que já vivia aqui há anos, trabalhando como químico. Ela chegara com o filho, recém egresso dos Conservatórios de Riga e de Berlim; na verdade, um excelso pianista que fez toda a sua carreira como pianista do Teatro Municipal de São Paulo. Liuba era uma grande cantora folclórica, não apenas na Rússia, mas em vários outros países, como Alemanha, França, Itália, Estônia, Lituânia, Letônia; tinha um repertório variado em diversos idiomas. Ela guardava jornais que a equipararam a Jane MacDonald e a uma série de cantoras populares que faziam excursões pelos diferentes países, o que, na época, era muito valorizado. Ela havia estudado canto tanto em Moscou como no Cáucaso, de onde ela viera, particularmente em Tiflis e, em 1929, tinha se aperfeiçoado na Itália, numa época em que o Fascismo parecia ter resolvido os problemas italianos, e época da qual ela guardava gratas recordações. Seus pais eram de família da alta burguesia. Seu pai era banqueiro e, com o advento da Revolução, por ele recebida com entusiasmo, havia perdido não apenas a posição, mas, devido ao início da Guerra Civil, também as condições mínimas de permanência no Cáucaso. Morreu logo em seguida. Os vários membros da família partiram para diferentes lugares. Ela, o filho Oleg e sua mãe foram 
para a Letônia, onde o filho ingressou no Conservatório de Riga; ela continuou com as suas excursões de canto. O marido havia ingressado nas fileiras do Exército Branco, um exército de resistência ao Regime Socialista, que havia sido constituído para combater a Revolução. Seu destino, portanto, era permanecer fora da já URSS; no entanto, pelas vicissitudes da guerra, ele acabou sendo preso e liquidado pelos nazistas, apesar de pertencer ao Exército Branco e de não ser, portanto, nem socialista nem bolchevique. Liuba tinha conseguido tirar o filho e a mãe de Riga, na época já ocupada pelos nazistas, graças ao canto, por falar perfeitamente alemão e ser conhecida como cantora. Ela levouos até a Alemanha, de onde, uma vez terminada a Guerra, eles seriam expatriados caso tivessem convite de algum outro país, ou devolvidos à URSS caso não o tivessem. Como eles tinham esse convite do irmão, vieram ao Brasil. Aqui, ela cantou em diversas rádios e tentou levar adiante a sua arte, mas isso não lhe foi possivel; e ela começou, então, a dar aulas de canto e de russo. Eu a conheci por ocasião da elaboração da minha tese de doutorado. A tese era sobre Velimir Khlébnikov, um poeta bastante dificil de ser traduzido. Tendo ouvido falar dela por Sofia Angelides, uma colega que já era sua aluna, eu me dirigi a ela à procura das fontes mais antigas possiveis, que pudessem me interpretar a época em que viveu Khlébnikov. Ele morreu na década de 1930 e, portanto, ela fora testemunha ocular daquele período. Foi-me extremamente valiosa por poder decifrar as alusões e as referências que se encontram esparsas na poesia de Khébnikov que, para quem não tivesse vivência daqueles lugares e daqueles tempos, seria uma tarefa praticamente impossível. Nós traduziamos seus poemas e, na verdade, eu escolhi como objeto da tese um conto chamado "Ka" que, por ser narrativa, era menos sintético do que a poesia. A tradução decorreu sem lacunas e permitiu-me ver que, realmente, Liuba Kusnetsova era, além de testemunha ocular e perfeita conhecedora do idioma (que ela enunciava de forma extremamente privilegiada justamente por ter se dedicado à música e ao canto) uma grande personalidade, uma grande pessoa. E, terminada a tese, eu continuei com as visitas semanais e escolhi como objeto de estudo Marina Tsvetáieva. Conforme descrevo no livro, o encontro com Marina Tsvetáieva deve-se à publicação de Poesia Russa Moder- 
na, por Boris Schnaiderman e pelos irmãos Campos, que incluíram alguns dos poemas dela na coletânea. Eu me apaixonei pela maneira de ela sintetizar, de escrever e de ousar, e procurei as obras completas, tanto na URSS, onde estive três vezes, como em Paris, onde há um interesse muito grande até hoje pela literatura russa, e onde encontrei as obras de Tsvetáieva e obras sobre ela. Nós praticamente passamos os dez anos seguintes do nosso relacionamento lendo Marina Tsvetáieva. Liuba morreu com mais de noventa anos.

Belkiss Rabello: Durante praticamente toda a sua vida, Marina Tsvetáieva enfrentou sofrimentos grandes e importantes: perdeu entes queridos, exilou-se fora de seu pais, conheceu uma miséria realmente cruel, solidão, etc. e, no fim, suicidou-se. No prefácio do livro, a senhora cita alguns elementos constantes, e aponta também várias diferenças, várias fases na obra de Tsvetáieva. Que relações concretas poderiam ser apontadas entre os versos, ou a prosa, da escritora e os diferentes periodos de sua vida? Certamente sua obra refletiu cada etapa, as tragédias, as dificuldades. Onde, precisamente, as mudanças são mais evidentes? No tema, no estilo, no léxico, no tom...?

Aurora Bernardini: Compor versos era uma espécie de religião para Marina Tsvetáieva; ou seja, não havia dia que ela não dedicasse ao menos parte da manhã à composição de versos. Ela mesma descreve isso em diferentes páginas de seu diário. Equando, por razões várias, não conseguia ter essas horas a sua disposição, ela sentia-se em falta para com a grande arte, a arte de poetar que, segundo ela, era um dom divino, um dom que Deus havia lhe dado e pelo qual ela tinha de responder, embora não fosse propriamente uma pessoa religiosa no sentido de ser crente. Ela tinha religiosidade, um ritual de vida e princípios que ela praticava e aos quais ela aderia firmemente. $O$ fato de escrever era função das condições da vida. Há grandes hiatos na sua escrita, que são justamente os momentos em que a sua vida, a sua existência não o permitiram. Por exemplo, quando voltou para a Rússia em 1936, poucos anos antes de se suicidar (1941). Ela passou os últimos anos de sua vida naquele país, às vésperas da ocupação nazista e durante essa ocupação, com a guerra 
já eclodida. Foram períodos extremamente dificeis, sem moradia nem trabalho fixos, com um filho adolescente que, além da problemática da idade, era extremamente ousado: ele participava de um grupo que, sobre os telhados dos prédios de Moscou, observava os aviões inimigos e dava o alarme. Ela era muito compenetrada em seu papel de mãe e também muito ligada afetivamente ao filho, e simplesmente não tinha tranqüilidade para escrever. Então, há hiatos; mas, de modo geral, ela nunca deixou passar um dia sem escrever. Primeiramente poesia e, depois de emigrada para Berlim, Praga e arredores de Paris; ou seja, durante os dezessete anos que passou no estrangeiro, também escreveu prosa. Ela passou a se dedicar à prosa porque era um gênero considerado mais publicável. Os editores achavam a prosa menos dificil de ser entendida do que os poemas que ela compunha, que só poderiam, naturalmente, ser compreendidos em russo porque se trata de um tipo de poesia trabalhada, em que é dado um papel relevante às raízes das palavras e que não é traduzivel com felicidade para outros idiomas. É uma poesia muito dificil de se traduzir. A ligação entre vida e obra é uma ligação necessária, mas a arte, para ela, sempre foi uma transcendência, nunca foi o reflexo da realidade, de modo que o trabalho do poeta acontecia em torno de certos núcleos privilegiados. Há uma série que vai desde as bilinas russas, passando por Púchkin, Shakespeare, Pasternak, Mandelstam, o mestre, o aluno, as lendas da Rússia, Moscou, o folclore, até as velhinhas russas, as russalkas, os elfos, as criaturinhas dos bosques, as serpentes. Há uma gama muito variada de temas, inclusive engajados. Quando a Tchecoslováquia foi invadida pelos nazistas, ela escreveu um ciclo sobre esse país, um ciclo de poesia empenhada, extremamente contundente e de grande teor poético. Ou seja, ela achava que a poesia era uma força, e havia algumas tarefas que ela impunha a si mesma e que realizava através desse dom que ela reconhecia e valorizava extremamente: o dom da arte verbal. Ela tentou também escrever em francês, depois de mais de uma década vivida na França, onde aperfeiçoou seu conhecimento do idioma.

Num livro de cartas e diários íntimos, que será publicado em breve, ela acompanha os passos tanto de sua criação como de sua tradução. E as informações e observações que ela apre- 
senta são extremamente válidas até hoje para qualquer poeta ou tradutor.

Belkiss Rabello: Quem está traduzindo esse livro?

Aurora Bernardini: Eu mesma. Ele vai se chamar Uma vida sob o fogo. É um título curioso, porque o livro foi cuidado por Tzvetan Todorov, um crítico conhecido e um dos grandes divulgadores de Marina Tsvetáieva na França. Ele recolheu os seus diários, suas cartas e compôs o livro que, em francês, se chama Vivre dans le feu; ou seja, numa tradução literal, Viver no fogo que, por razões óbvias, não soava bem em português. Então, para não fugir muito ao título, decidiu-se chamá-lo Viver sob o fogo. O que Tzvetan Todorov fez foi um longo prefácio e o acompanhamento, capítulo por capítulo, dos textos, o que torna a leitura muito interessante e fluente, porque, a cada explicação, a cada acompanhamento, segue-se um texto de Marina Tsvetáieva, texto que foi fornecido em russo para a editora e traduzido por mim. Em resumo, eu traduzi os textos de Todorov e os diários e cartas mais importantes de Tsvetáieva. Eles esclarecem muitos pontos sobre sua vida e obra. É uma leitura apaixonante e o livro será publicado, acredita-se, até o fim de 2007, pela Editora Martins.

Belkiss Rabello: No ano passado, em um curso que ministrou no Departamento de Lingua, Literatura e Cultura Russas da USP, Serguiéi I. Nikliudov, professor convidado, disse que Marina Tsvetáieva inspirou-se muito na poesia folclórica russa. O que a senhora poderia comentar sobre este assunto, e que indicios da poesia folclórica a senhora encontrou no decorrer de seu trabalho de tradução da obra de Tsvetáieva?

Aurora Bernardini: Um dos poemas que mais me impressionaram, e que talvez melhor tenha saído na tradução, pertence justamente a esse filão folclórico; é um poema dedicado à deusa Ishitar. Nele, vemos como os russos incorporam alguns deuses do Oriente à tradição do folclore russo e como os relacionam a certos episódios marcantes de sua própria vida, por exemplo, à invasão dos tártaros. De um lado, a divina Ishitar, deusa protetora oriental e, de outro lado, Khan, o grande chefe tártaro, que 
rapta as donzelas e espalha terror pelas aldeias. O filão do folclore é extremamente acarinhado por Tsvetáieva. Os encantamentos que estão presentes também em outros poetas, como Khlébnikov, são por ela tratados de forma muito viva, com repetições onomatopéicas e abordam a traição amorosa, a velhice, a infância, o aparecimento de algum ser sobrenatural, certos hábitos que se conservam até hoje na vida cotidiana russa, como o modo de velar os mortos, as cerimônias do enterro, do casamento, da crisma e do batismo. Marina Tsvetáieva transfundiu tudo isso em seus poemas, valendo-se da inspiração desses hábitos enraizados no povo e que constituem a sua maneira de viver o folclore. Ela foi realmente uma grande pesquisadora; foi, principalmente, uma pessoa que viveu esses hábitos com a mesma atenção e com a mesma paixão com que ela vivia aquilo de que gostava.

Belkiss Rabello: Segundo Tvardóvski, Marina Tsvetáieva antecipara-se muito no que concerne às "descobertas" literárias atribuidas a poetas russos que a precederam. A senhora poderia apontar algumas delas? Poderia comentar essa afirmação?

Aurora Bernardini: Ela foi considerada surrealista, futurista e simbolista por excelência. O próprio Pasternak, em uma carta dirigida a ela - há uma intensa correspondência entre os dois diz o seguinte: "Você conseguiu realizar magicamente aquilo que os poetas simbolistas russos tentaram e não conseguiram." Ele a considera uma simbolista essencial. Mas, certamente, ela tem também traços do Cubo-Futurismo russo, ou seja, frases sincopadas, palavras que são explicáveis apenas pela escavação etimológica e que, aparentemente, muitas vezes não têm um sentido imediato, rimas irregulares, muitas vezes internas, e a tendência de escolher como tema qualquer assunto e qualquer objeto: uma árvore, uma flor, uma sombra, uma mesa, uma parede, ou seja, não havia preocupação em nobilitar o tema, traço eventualmente próprio do Simbolismo, ou em estranhá-lo, como era tendência do Surrealismo. Ela humanizava esse tema. Em suma, Tsvetáieva esteve no limiar desses três grandes movimentos: Simbolismo, Surrealismo e Futurismo. Depois, obviamente, desenvolveu uma poética própria, com elementos dessas escolas, mas muito particular e pessoal.

TRadTerm, 14, 2008, p. 243-253 
Belkiss Rabello: Apesar de uma sina tão trágica, parece difícil encontrar em seu trabalho elementos claramente mórbidos. Ao contrário, o que vemos é uma poesia cheia de vida, de amor, de compaixão, talvez, pelo ser humano. Não é verdade?

Aurora Bernardini: Sim. Mas é verdade também que ela era extremamente seletiva. Ela gostava dos seres humanos em tese, mas, na prática, tinha os seus eleitos, e isso se corrobora por suas posições. Ela escolhera um mote que deveria reger e essencializar sua postura: "Je ne deigne". Ou seja, uma certa áurea aristocrática que fazia com que ela tivesse uma auto-consideração extremamente elevada. Ela mesma dizia que, pelo fato de ser poeta, e de ter a ascendência que tinha, e que tanto prezava - seu pai fora professor universitário, criador do Museu Puchkin; sua mãe, grande musicista, e ambos dedicaram, direta ou indiretamente, a sua vida ao desenvolvimento da cultura na Rússia - fazia com que ela se sentisse uma eleita, uma conspiradora e, portanto, suas escolhas eram escolhas verdadeiras. Havia algumas generalizações às quais Marina Tsvetáieva era muito apegada: ela considerava o amor materno a primeira função da mulher e, por decorrência, o amor para com o próximo. Ela praticou esse amor acima de tudo e, em várias ocasiões, deixou de escrever devido à dedicação aos filhos. Sacrificou-se quando teve de escolher entre o marido e um amante na Tchecoslováquia, e abriu mão do amante, da aventura, da novidade, para ser fiel a um ser que ela acreditava depender dela, e pelo qual ela se sentia responsável. Ela tinha princípios aos quais se apegava, mesmo que não fosse a solução mais atraente. Tinha conceitos universais e práticas particulares.

Belkiss Rabello: Curiosamente, sua poesia não nos parece ser intimista, o que talvez a torne mais accessivel ao público não especializado...

Aurora Bernardini: Sim. Isso é uma grande verdade. Sua poesia tem grande valor porque escapa do pessoal, ou melhor, embora não se dando a ver a si própria, ela está colocando em si mesma todo o gênero feminino. São várias as suas admirações: Helena, Hipólita, a rainha das Amazonas, Akhmátova, alguma 
escritora importante que ela tivesse conhecido em sua permanência no estrangeiro, etc. Ela tinha alguns emblemas que lhe serviam de inspiração e nos quais ela se incluía. Por exemplo, embora escrevesse sobre Hipólita, estava escrevendo sobre si própria, e assim por diante. E havia uma galeria de figuras mitológicas gregas que ela desenvolveu em poemas, longos ou curtos, e que ampliou, quando esteve na França, com o conhecimento dos grandes poetas franceses, como Corneille e Racine, que também transformaram figuras mitológicas em protagonistas de tragédias, em geral mais extensas. Tsvetáieva tinha a capacidade de mitificar e de universalizar as suas componentes pessoais.

Belkiss Rabello: Levando em conta o trabalho poético de Marina Tsvetáieva, como a senhora qualificaria a sua prosa? E quais as caracteristicas principais dessa prosa? Trata-se, como preferem algumas pessoas, de uma espécie de anti-prosa?

Aurora Bernardini: A prosa de Marina Tsvetáieva é uma prosa inspirada, que tem muito do poético. Por exemplo, um texto como "Meu Puchkin" é um texto em que ela começa a relembrar seus primeiros anos de vida, quando tinha cinco, sete anos de idade. Nele, percebemos como ela sentia Puchkin enquanto criança, numa linguagem infantil; essa linguagem evolui, acompanhando "Meu Puchkin" pelas diferentes etapas da vida; nele, a linguagem está acompanhando o estilo e a idade da poeta. Há outros textos mais memoralísticos, em que a história de sua família paterna e materna é transformada em prosa, uma prosa bastante renovada. O memorialismo é sempre praticado com extrema sensibilidade, com muita subjetividade. Os acontecimentos são filtrados pelo sentir da poeta enquanto criança, enquanto jovem, enquanto mulher, e são textos que proporcionam uma leitura de algo realmente apaixonado. Na verdade, seus textos são sempre apaixonados, não são textos “objetivos". Curiosamente, ela consegue ser tão universal na poesia quanto subjetiva na prosa.

Belkiss Rabello: Seriam seus textos em prosa tão densos e concisos quanto sua poesia? Pode-se dizer que se trata da prosa de um poeta? 
Aurora Bernardini: É a prosa de um poeta, mas, curiosamente, ela é tão concisa na poesia quanto divagante na prosa. Na prosa ela é muito espraiada. Tanto é verdade que há críticos que a acham excelente poeta e péssima prosadora. Eu, pessoalmente, sem dúvida prefiro a poesia, mas existem textos em prosa que são notáveis. Na prosa ela permitiu-se, às vezes, excessos de lirismo que não se permitia na poesia, nos seus diários ou cartas, onde prima pela contundência.

Belkiss Rabello: Os criticos parecem sentir dificuldade em classificar a obra de Tsvetáieva. Seu leque de estilos é bastante amplo: poemas épicos, poemas líricos, peças de teatro, contos populares, prosa, etc. Que traços da escritora acompanharam-na sempre, independentemente do gênero literário?

Aurora Bernardini: Realmente é um fato a diferenciação dentro do gênero. Na poesia, Marina Tsvetáieva mostrou uma grande versatilidade. Como você mesma disse, ela escreveu poemas épicos, poemas folclóricos, poemas líricos, poemas dedicados a personalidades como Puchkin, Anna Akhamátova, Blok, Mandelstam, Pasternak, Rilke, pessoas que a inspiraram. Nesses poemas, ela adequou o estilo dela ao estilo de cada um desses poetas. Dentro do gênero poesia há uma grande variedade em que ela sobressaiu-se e em que conseguiu ser excelente. Entretanto, como eu me dediquei mais ao estudo dos poemas curtos, mais breves, encontrei neles a felicidade da sintese. Tirante dois poemas longos que, talvez, sejam os mais inspirados que ela tenha jamais escrito, o "Poema da Montanha" e o "Poema do Fim", compostos em estado de paixão amorosa e que, devido ao fato de ela se considerar uma poeta inspirada, tenham, provavelmente, sido o ápice da sua composição poética.

Belkiss Rabello: Então, o mote do conjunto da obra poética de Tsuetáieva era...

Aurora Bernardini: "Je ne daigne pas" (em francês arcaico, como ela quis: "Je ne deigne") ou seja, "Não vou me rebaixar a; jamais vou me curvar a fazer algo que não esteja dentro dos padrões 
que fazem de mim o que sou". E, de fato, ela viveu esse mote até conseqüências extremas.

Belkiss Rabello: Além de se servir da concisão que a lingua russa oferece, como ela trabalha essa lingua em sua poesia?

Aurora Bernardini: Ela trabalha imprimindo um ritmo e uma rima obrigatórios. Ela acha que a própria natureza da poesia exige rima e ritmo. Não concebe poesia sem rimas, embora reconheça o valor de certos versos isolados. Lógico, uma frase solta, para ela, tinha um valor emblemático. Ela mesma, nos diários, comenta uma frase a respeito de uma planta: "Está aí um verso que não foi incluído num poema, um verso que encerra uma percepção privilegiada, mas com o qual não se compôs um poema. Ele foi desperdiçado". Existem versos isolados de grande poeticidade. Mas eles só passam a ter realmente valor quando incorporados a um poema. Então, além da questão léxica, das palavras em si, que são palavras muitas vezes escavadas do ponto de vista etimológico, compostas de raízes, ou abreviadas, a dificuldade de traduzir Marina Tsvetáieva está em conseguir conferir à tradução o ritmo e a rima, que são imprescindíveis a ela.

Belkiss Rabello: Nos poemas que integram o livro "Indicios Flutuantes", chama a nossa atenção o uso constante do travessão, obviamente usado por ela como elemento musical que nos indica um tempo de espera e que nos anuncia algo que se quer ressaltar. É uma pausa. A sua tradução obedece e conserva a maior parte deles. Em algum momento a pontuação empregada por ela tornou-se obstáculo na tradução? Cite, se for possivel, alguns problemas sérios que a senhora teve de enfrentar ao traduzir os poemas desse livro. Fale-nos um pouco mais sobre traduzir a obra poética de Marina Tsuetáieva.

Aurora Bernardini: Além de ser um traço da sintaxe e da gramática russas - pois o travessão mostra a existência do verbo "ser" no presente, embora omitido - há também o uso particular desse sinal, acrescentado por Tsvetáieva. O que significa o travessão para ela? Tiniánov teve ocasião de dizer em seu $O$ proble- 
ma da palavra poética que as reticências e o travessão, ou ainda o ponto, podem indicar um equivalente do verso; o leitor pode imaginar aquilo que está subentendido atrás desses sinais. É pausa, mas também é signo de algo que não foi dito. O travessão é um aglutinador, uma forma de sintetizar. Esse é um dos aspectos que a aproximam do Cubo-Futurismo: a raiz de uma palavra, ou uma curta alusão que equivale a uma frase mais longa, a um verso mais longo, a uma explicação mais detalhada. A alusão é fundamental em Marina Tsvetáieva. Esse é mais um exemplo da dificuldade de tradução de sua poesia, pois uma alusão que pode ser percebida pelo leitor russo já não o é pelo leitor brasileiro. O brasileiro tem outro sistema de referência e outro mundo cultural atrás de si. Então, conseguir traduzir essas alusões de modo que elas forneçam algo próximo àquilo que representam para o leitor russo foi uma dificuldade muito grande. Tudo isso sem trair o espírito do poema... a transposição de uma ambiência a outra não foi por mim considerada. Fiz questão de conservar a ambiência russa. Algumas vezes, embora raras, recorri a notas para que fosse possivel entender tais alusões. E, na verdade, escolhi os poemas em função da sua traduzibilidade; ou seja, houve muitos poemas admiráveis em russo que não saíram bem em português, não conseguiram dar o espírito através de minha tradução. Eles não foram incluídos nessa coletânea que, por conseguinte, já é uma escolha de poemas que teriam permitido essa transposição sem ferir o espírito do original.

Guarujá, 13 de outubro de 2007. 